\title{
Inhibition of proliferation and migration and induction of apoptosis in glioma cells by silencing TLR4 expression levels via RNA interference
}

\author{
YINGZI LIU ${ }^{1}$, YINGCHAO JU ${ }^{2}$, JIANGHUI LIU ${ }^{3}$, YUETONG CHEN ${ }^{3}$, XIANGRAN HUO $^{3}$ and LIANG LIU ${ }^{3}$ \\ ${ }^{1}$ Department of Neurosurgery, ${ }^{2}$ Animal Experimental Center, ${ }^{3}$ Tumor Institute, \\ The Fourth Hospital of Hebei Medical University, Shijiazhuang, Hebei 050011, P.R. China
}

Received February 12, 2020; Accepted September 23, 2020

DOI: $10.3892 / \mathrm{ol} .2020 .12274$

\begin{abstract}
The objective of the present study was to investigate the expression levels of toll-like receptor 4 (TLR4) in glioma cells and the mechanisms underlying its regulatory effects on proliferation, migration and apoptosis of glioma cells. A total of three TLR4 silencing short hairpin (sh)RNA plasmids were established, and Lipofectamine ${ }^{\circledR}$ was used to the transfect the human glioma cell line U-87MG. Transfection efficiency was measured via flow cytometry. The interference plasmid exhibiting the largest silencing effect on TLR4 was screened for subsequent experiments using puromycin. Reverse transcription-quantitative PCR and western blot analysis were used to detect the TLR4 gene and protein expression levels, respectively, in stably transfected cells. Flow cytometry measured cell cycle and apoptosis and a wound healing assay was employed to assess the migration ability of transfected cells. The proliferation of transfected cells was detected using Cell Counting Kit-8 assay. TLR4-sh2 exhibited the highest transfection efficiency. Following transfection of U-87MG cells with TLR4-sh2 and negative control (NC) plasmids for $48 \mathrm{~h}$ and screening by puromycin, stable transfected cells were named U-87MG-Sh and U-87MG-NC cells respectively. The TLR4 gene and protein expression levels in the U-87MG-Sh cells were significantly lower than in U-87MG and U-87MG-NC cells. The apoptosis rate and the percentage of $\mathrm{G}_{0 / 1}$ cells were significantly higher, whereas the cell proliferation rate was notably lower, in U-87MG-Sh cells than in the U-87MG-NC and U-87MG cells. The proliferation rate and the cell migration ability of U-87MG-Sh cells were significantly lower than those of U-87MG-NC and U-87MG cells. TLR4 is
\end{abstract}

Correspondence to: Professor Liang Liu, Tumor Institute, The Fourth Hospital of Hebei Medical University, 12 Jiankang Road, Shijiazhuang, Hebei 050011, P.R. China

E-mail: aliangdaziran@163.com

Key words: glioma, toll-like receptor 4, migration, proliferation, RNA interference associated with the proliferation of glioma cells. Inhibition of TLR4 expression levels significantly inhibited proliferation of glioma cells and induced apoptosis. The present study provided insights into the mechanisms associated with the development, progression and invasion ability of glioma cells.

\section{Introduction}

Glioma is a type of primary brain cancer, which is characterized by high prevalence and gross invasion and is lethal to human health $(1,2)$. It is estimated that $>19,000$ new cases of glioma are diagnosed each year, with an age-adjusted average annual incidence rate of 6.24 per 100,000 individuals in the United States between 2007 and 2011 (3). Glioma cells are aggressive and can develop resistance to conventional therapies; treatment options (such as surgery, radiotherapy and chemotherapy) exhibit poor efficiency and the average survival time of patients with high-grade glioma is $<1$ year (4). With the development of molecular biology, the potential of immunotherapy as a treatment for glioma has been investigated. It is necessary to understand immunotolerance and immunomodulation of glioma to develop an immunotherapy strategy. Toll-like receptors (TLRs) have been identified as key pattern recognition receptors (PRRs). The release of inflammatory mediators and the activation of innate immunity are primarily caused by TLRs, which induce signal transduction via recognition of pathogen-associated molecular patterns (PAMPs) and certain endogenous ligands $(5,6)$. TLRs are also implicated in the pathogenesis of numerous types of immune-associated disease in human (7-9). For example, Tian et al (10) reported that mulberry leaf decreased inflammation and insulin resistance in type 2 diabetic mice via TLRs and the insulin signaling pathway. A total of 10 types of TLR have been identified in humans, among which TLR4 exhibits a significant association with the biological behavior of tumors $(11,12)$. This finding is of interest from a tumor immunity perspective. Although TLRs mediate innate immunity, they are not unique to the innate immune system; in addition to immune cells (monocytes/macrophages, T/B lymphocytes and dendritic cells), they are also expressed in certain non-immune cells (endothelial, smooth muscle and tumor cells) (13). TLR expression levels in 
tumor cells are important for tumor genesis and development, and is an area of interest for tumor research (14). Among TLRs, TLR4 is more commonly expressed in different types of tumor, such as colon cancer and ovarian carcinoma, compared with other TLRs $(15,16)$. High expression levels of TLR4 accelerate tumor proliferation and mediate tumor immune escape $(17,18)$. Hence, the present study aimed to investigate the association between TLR4 and the development of human glioma, and to provide an experimental basis for understanding of the molecular mechanism underlying proliferation regulation of human glioma cells.

\section{Materials and methods}

Reagents and equipment. All-in-One ${ }^{\mathrm{TM}}$ quantitative (q)PCR Primer (cat. no. HQP054754) and H-TLR4-short hairpin (sh)RNAs 1-3 (cat. nos. HSH054754-CU6-a, b, c and CSHCTR001-CU6) were purchased from GeneCopoeia, Inc. Lipofectamine ${ }^{\circledR} 2000$ was obtained from Invitrogen (Thermo Fisher Scientific, Inc.). High-purity Plasmid Mini-Preps kit was obtained from Tiangen Bioctech Co., Ltd.. Minimum Essential Medium (MEM) and bovine serum albumin were obtained from Gibco (Thermo Fisher Scientific, Inc.). RNAiso total RNA extraction reagent, HiScript II 1st Strand complementary cDNA Synthesis kit and qPCR SYBR Green Master mix were acquired from Vazyme Biotech Co., Ltd.. Annexin V-PE/7-AAD kit and Matrigel Matrix Basement Membrane were purchased from BD Biosciences. FC-500 flow cytometer (Beckman Coulter, Inc.), the PCR instrument (Eppendorf) and Mx3000P fluorescence quantitative PCR instrument (Agilent Technologies, Inc.) were also used.

Cell lines. The U-87MG cell line (cat. no. CL-0238) was obtained from Procell Life Science \& Technology Co., Ltd. STR profiling, Y-chromosome paint and Q-band assay confirmed that the cell line is male in origin (performed by Procell Life Science \& Technology Co., Ltd). Based on current literature, the cell line is likely a glioblastoma of unknown origin (19). The U-87MG cell line had a stable passage in the laboratory, and was cultured in MEM containing 10\% FBS, $100 \mathrm{U} / \mathrm{ml}$ penicillin and streptomycin. Cells were sustained in an incubator at $37^{\circ} \mathrm{C}$ with $5 \% \mathrm{CO}_{2}$.

RNA interference lentiviral vector construction. GeneCopoeia, Inc. synthesized the interference plasmids [cat. nos. HSH054754-CU6-a,b,c and CSHCTR001-CU6; accession no. NM_003266.3 (Homo sapiens TLR4, mRNA)]. The vector used was psi-U6.1 (GeneCopoeia, Inc.). A total of three shRNAs were designed to interfere with the TLR4 gene. shRNA target sequences are presented in Table I.

Transfection of shRNA-containing plasmids into U-87MG cells. shRNA-containing plasmids $(4 \mu \mathrm{g})$ were transfected into U-87MG cells, in order to silence the TLR4 gene. For reagent 1, $244 \mu 1$ MEM (FBS- and antibiotic-free) was used to buffer $6 \mu$ l Lipofectamine ${ }^{\circledR} 2000$. For reagent 2, $240 \mu 1$ MEM (FBS- and antibiotics-free) was used to dilute $10 \mu \mathrm{l}$ shRNA plasmids [containing $4 \mu \mathrm{g}$ TLR4-sh1-3 and negative control (NC) plasmids]. Both reagents were placed at room temperature for $5 \mathrm{~min}$.

U-87MG cells in the logarithmic phase of growth were collected and seeded in 6-well plates at a density of $4 \times 10^{5}$ cells/well. Cells were transfected until they reached 85-90\% confluence. MEM (FBS- and antibiotics-free) was used to wash cells twice, then $2 \mathrm{ml} \mathrm{FBS-} \mathrm{and} \mathrm{antibiotic-free}$ MEM was added into each well. After placing the mixture containing reagents 1 and 2 at room temperature for $20 \mathrm{~min}$, $200 \mu \mathrm{l}$ of this mixture was added into wells. After $6 \mathrm{~h}, \mathrm{FBS}$ and antibiotics-free MEM was replaced with complete culture medium. Following transfection for $48 \mathrm{~h}$, cells were observed under a fluorescence microscope (magnification, x100). Untreated cells were considered as the blank control group. Cells only treated with Lipofectamine were considered as the liposome group.

Identifying stably transfected cells with puromycin. The TLR4-sh2 plasmid was chosen for subsequent siRNA experiments. After U-87MG cells were transfected with the TLR4-sh2 plasmid and the negative control plasmid for $48 \mathrm{~h}$, the cells were diluted with MEM and cultured in a 6-well plate at a density of $5 \times 10^{4}$ cells/well. Subsequently, $600 \mathrm{ng} / \mathrm{ml}$ puromycin was added into each well. The non-transfected U-87MG cells were used as the blank control group. After the cells were cultured for 14 days at $37^{\circ} \mathrm{C}$ with $5 \% \mathrm{CO}_{2}$, the surviving cells were considered as stably transfected cells. The cells transfected with TLR4-sh2 were named U-87MG-Sh, while the cells transfected with the negative control (NC) plasmid were named U-87MG-NC.

Evaluating transfection efficiency via flow cytometry. Following transfection for $48 \mathrm{~h}$, cells were collected and washed with PBS once. Next, flow cytometry was performed using a FC-500 type flow cytometer (Beckman Coulter, Inc.) to measure green fluorescence in cells. Transfection efficiency was identified as the proportion of cells expressing green fluorescence compared with all observed cells. Green fluorescence was measured using the EXPO32 ADC v1.2 software (Beckman Coulter, Inc.).

Evaluating TLR4 mRNA expression levels via reverse transcription-quantitative $(R T-q) P C R$. Following transfection for $48 \mathrm{~h}$, cells were collected and washed with PBS twice. Next, based on the one-step method (20), total RNA was extracted by adding $1 \mathrm{ml}$ RNA isolator (Vazyme Biotech Co., Ltd.). As the template for PCR, cDNA was synthesized using the HiScript II First Strand cDNA Synthesis kit according to the manufacturer's protocol (Vazyme Biotech Co., Ltd.). The internal reference was human GAPDH. The fluorescent signal was obtained using SYBR-Green I. Based on the manufacturer's protocol of the qPCR SYBR-Green Master Mix kit (Vazyme Biotech Co., Ltd.), qPCR was performed. The thermocycling conditions were as follows: $95^{\circ} \mathrm{C}$ for $5 \mathrm{~min}$ (pre-denaturation), followed by 40 cycles at $95^{\circ} \mathrm{C}$ for $10 \mathrm{sec}$ and $60^{\circ} \mathrm{C}$ for $30 \mathrm{sec}$, and dissociation at $95^{\circ} \mathrm{C}$ for $15 \mathrm{sec}$, $60^{\circ} \mathrm{C}$ for $1 \mathrm{~min}$ and $95^{\circ} \mathrm{C}$ for $15 \mathrm{sec}$. For each sample, each experiment was repeated three times. The forward primer for GAPDH was 3'-CACTACCGTACCTGACACCA-5' and the reverse primer was 3'-ATGTCGTTGTCCCACCACCT-5'. 
Table I. Short hairpin RNA target sequences.

\begin{tabular}{lcccl}
\hline Clone name & Symbol & Location & Length, bp & Target sequence (5'-3') \\
\hline HSH054754-CU6-a(OS397039) & TLR4 & 890 & 21 & GCTCACAATCTTATCCAATCT \\
HSH054754-CU6-b(OS397040) & TLR4 & 678 & 21 & GGTGTGAAATCCAGACAATTG \\
HSH054754-CU6-c(OS397041) & TLR4 & 887 & 21 & GTGGCTCACAATCTTATCCAA \\
\hline
\end{tabular}

TLR4, toll-like receptor 4 .

The TLR4 sequence was synthesized by GeneCopoeia, Inc. (cat. no. HQP054754). The relative expression levels of TLR4 mRNA $\left(\triangle \mathrm{Cq}=\mathrm{Cq}_{\mathrm{TLR} 4}-\mathrm{Cq}_{\mathrm{GAPDH}}\right)$ were calculated using the $2^{-\Delta \Delta \mathrm{Cq}}$ method (21). RT-qPCR was used to evaluate the silencing effect of shRNA TLR4 expression levels and to select the interference plasmid with the greatest silencing effect.

Measuring TLR4 protein expression levels via western blotting. U-87MG-Sh, U-87MG-NC and U-87MG cells were collected in the logarithmic phase of growth and washed with cold PBS twice. Total protein was collected by adding cell lysis solution (RIPA:PMSF, 100:1; Beijing Solarbio Science $\&$ Technology Co., Ltd.). The protein concentration was evaluated via bicinchoninic acid assay. Protein (50 $\mu \mathrm{g} / \mathrm{lane})$ was separated via $10 \%$ SDS-PAGE then transferred to PVDF membranes before being blocked overnight at $4^{\circ} \mathrm{C}$ with $5 \%$ skimmed milk. Next, rabbit-anti-human $\beta$-actin $(1: 4,000$; cat. no. ab8227; Abcam) or mouse-anti-human TLR4 (1:500; cat. no. ab22048; Abcam) monoclonal antibodies were added for incubation at room temperature for $1 \mathrm{~h}$. The membrane was washed three times, then incubated at room temperature for $2 \mathrm{~h}$ with horseradish peroxidase-conjugated goat anti-mouse and anti-rabbit secondary antibodies (1:20,000; cat. nos. ab205719 and ab205718, respectively; Abcam). The antigen-antibody reaction was visualized by detection using an ECL assay (EMD Millipore). Relative expression levels of TLR4 protein were normalized to those of $\beta$-actin using Odyssey v3.0 software (LI-OR Biosciences). A total of three independent repeats were performed.

Flow cytometric analysis of cell cycle. U-87MG-Sh, U-87MG-NC and U-87MG cells were collected in the logarithmic phase of growth and washed with cold PBS twice. Cells were fixed with $70 \%$ ethanol at $4^{\circ} \mathrm{C}$ for $24 \mathrm{~h}$. Cells were washed twice with PBS and cell density was adjusted to $1 \times 10^{7} / \mathrm{ml}$. Then, $100 \mu \mathrm{l}$ cell suspension was collected and $500 \mu \mathrm{l}$ propidium iodide including a ribonuclease (BD Biosciences) was added for $30 \mathrm{~min}$ at $4^{\circ} \mathrm{C}$. Flow cytometry was performed using a FC500 type flow cytometer (Beckman Coulter, Inc.), and the Multicycle AV v6.0 software (Beckman Coulter, Inc.) was used to estimate the percentage of cells in each stage of the cell cycle. The proliferation index (PI) was calculated as the percentage of cells in the $\mathrm{S}$ and $\mathrm{G}_{2} / \mathrm{M}$ phases against all cells, representing cell proliferation activity.

Flow cytometry analysis of apoptosis. U-87MG-Sh, U-87MG-NC and U-87MG cells were collected in the logarithmic phase of growth and washed with cold PBS twice.
Then, $1 \times 10^{6}$ cells were collected and washed with PBS once and suspended in $100 \mu \mathrm{l} 1 \mathrm{X}$ binding buffer. Next, cells were incubated on ice with $10 \mu \mathrm{l}$ Annexin V-PE for $15 \mathrm{~min}$. Then, $380 \mu \mathrm{l} 1 \mathrm{X}$ binding buffer and $10 \mu \mathrm{l}$ 7-AAD were separately added, before being placed on ice for $15 \mathrm{~min}$ in the dark, washed and suspended in $1 \mathrm{ml}$ PBS. Flow cytometry (FC500 type flow cytometer; Beckman Coulter, Inc.) was used to evaluate cell apoptosis. Immunofluorescence data and apoptosis rate were measured using the EXPO32 ADC v1.2 software (Beckman Coulter, Inc.).

Measuring cell migration by wound healing assay. On the back of the 6-well culture plate, lines (5/well) at $0.5 \mathrm{~cm}$ intervals were drawn. Then, $\sim 5 \times 10^{5}$ cells (U-87MG-Sh, U-87MG-NC and U-87MG) were seeded into each well and cultivated overnight at $37^{\circ} \mathrm{C}$ to $100 \%$ confluence. The next day, scratches perpendicular to the lines on the back of the 6-well plate were drawn on cells using a $10-\mu 1$ pipette tip. In order to remove unattached cells, cells were washed with PBS three times and cultured for $24 \mathrm{~h}$ at $37^{\circ} \mathrm{C}$ in serum-free MEM. The cell culture condition was $37^{\circ} \mathrm{C}$ with $5 \% \mathrm{CO}_{2}$, and images were captured at 0 and $24 \mathrm{~h}$ using an inverted light microscope (TE2000; Nikon Corporation; magnification, x100). The area of wound healing was assayed using ImageJ 1.42 software (National Institutes of Health).

Detecting cell viability by cell counting Kit-8 (CCK-8) assay. Monolayer cultured U-87MG-Sh, U-87MG-NC and $\mathrm{U}-87 \mathrm{MG}$ cells were digested at $37^{\circ} \mathrm{C}$ for $30 \mathrm{sec}$ using $0.25 \%$ trypsin. Then, MEM supplemented with $10 \%$ FBS (Gibco; Thermo Fisher Scientific, Inc.) was used to prepare the cell suspension. The cell density was adjusted to $1 \times 10^{4}$ cells $/ \mathrm{ml}$ and cells were seeded into 96 -well plates before being cultured in the incubator for cell adherence. Following incubation at $37^{\circ} \mathrm{C}$ with $5 \% \mathrm{CO}_{2}$ for $24 \mathrm{~h}, 20 \mu \mathrm{l}$ CCK-8 (Wuhan Boster Biological Technology, Ltd.) was added to each well and the plate was incubated for $4 \mathrm{~h}$ at $37^{\circ} \mathrm{C}$ according to the manufacturer's protocol. The $450 \mathrm{~nm}$ optical density wavelength was read via a microplate spectrophotometer, calibrated using the blank well. Growth inhibitory rate was calculated as $1-\mathrm{A} 450 \mathrm{U}-87 \mathrm{MG}-\mathrm{Sh}, \mathrm{U}-87 \mathrm{MG}-\mathrm{NC}$ or U-87MG cells/A450 U-87MG cells) x100\%.

Statistical analysis. All data are presented as the mean \pm SD $(n=3)$. One-way ANOVA was performed to compare multiple samples, followed by Tukey's post hoc test. Data were analyzed using SPSS software (version 21; IBM Corp.). $\mathrm{P}<0.05$ was considered to indicate a statistically significant difference. 
A
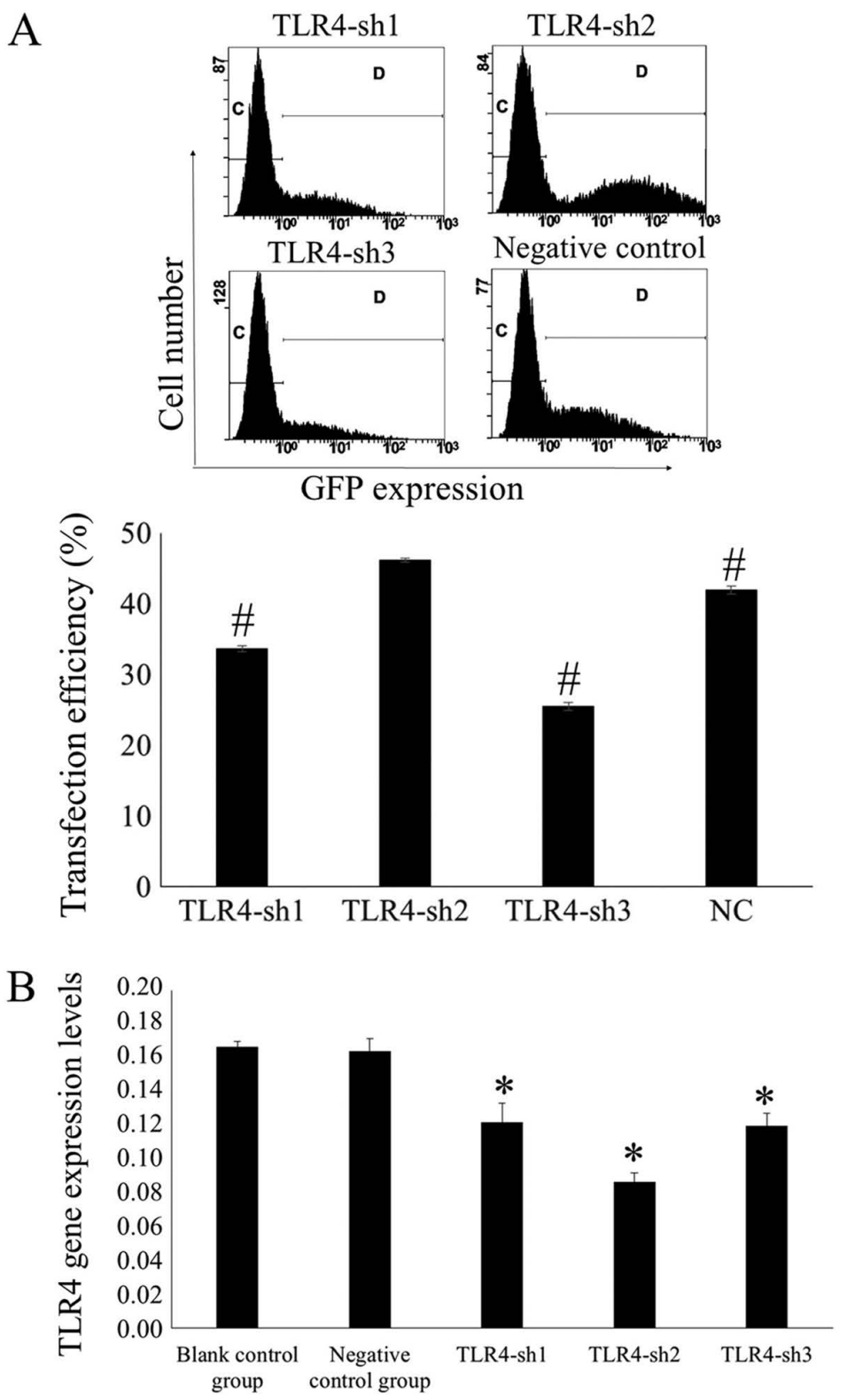

Figure 1. Silencing TLR4 in U-87MG cells using shRNA plasmids. (A) Transfection efficiency was evaluated using flow cytometry. The percentage of cells expressing green fluorescence measured using flow cytometry represents the transfection efficiency. "P<0.01 vs. TLR4-sh2. The letters "C" and "D" represent the gate of flow cytometry. (B) Expression levels of TLR4 mRNA in transfected cells using fluorescence reverse transcription-quantitative PCR. "P $<0.05$ vs. blank and negative control. $n=3$. TLR4, toll-like receptor 4; sh, short hairpin RNA.

\section{Results}

Silencing of TLR4 in U-87MG cells using shRNA plasmid transfection and evaluation of transfection efficiency and TLR4 mRNA expression levels via flow cytometry and fluorescence $R T-q P C R$. Green fluorescence expression levels in U-87MG cells transfected with H_TLR4-sh1, H_TLR4-sh2, H_TLR4-sh3 and NC plasmid were observed via fluorescence microscope. No green fluorescence was detected in non-transfected cells (blank control) and U-87MG cells in the liposome group.

Flow cytometry was used to measure transfection efficiency after $48 \mathrm{~h}$. Results demonstrated that the transfection efficiency was $33.66 \pm 0.40,46.20 \pm 0.31,25.49 \pm 0.60$ and $41.94 \pm 0.55 \%$ in the H_TLR4-sh1, H_TLR4-sh2, H_TLR4-sh3 and NC groups, respectively. In the H_TLR4-sh2 group, the transfection efficiency was significantly higher compared with the other groups $(\mathrm{P}<0.01$; Fig. $1 \mathrm{~A})$.

It was indicated that the TLR4 mRNA expression levels in U-87MG cells transfected with H_TLR4-sh1, H_TLR4-sh2, H_TLR4-sh3 and NC plasmid were $0.1219 \pm 0.0116$, $0.0867 \pm 0.0054,0.1201 \pm 0.0071$ and $0.1643 \pm 0.0074$, respectively, whereas that in the blank control group was $0.1669 \pm 0.0029$. The TLR4 mRNA expression levels were significantly lower in U-87MG cells transfected with H_TLR4-sh2 than in the other groups $(\mathrm{P}<0.05$; Fig. 1B). This illustrated that H_TLR4-sh2 possessed the largest silencing effect. Hence, H_TLR4-sh2 was selected for subsequent experiments.

TLR4 silencing decreases TLR4 mRNA expression levels. Following treatment with $600 \mathrm{ng} / \mathrm{ml}$ puromycin for 14 days, all cells in the blank control group died. A notable number 


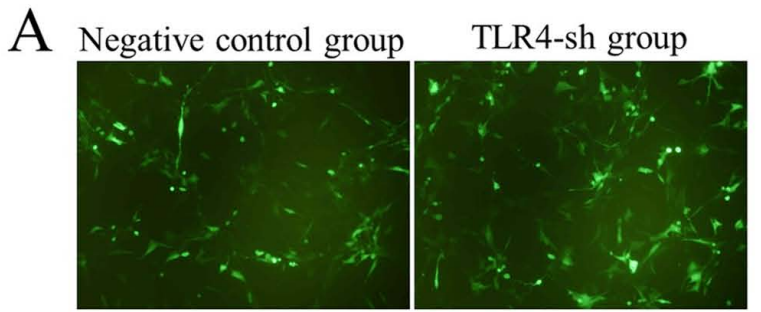

C

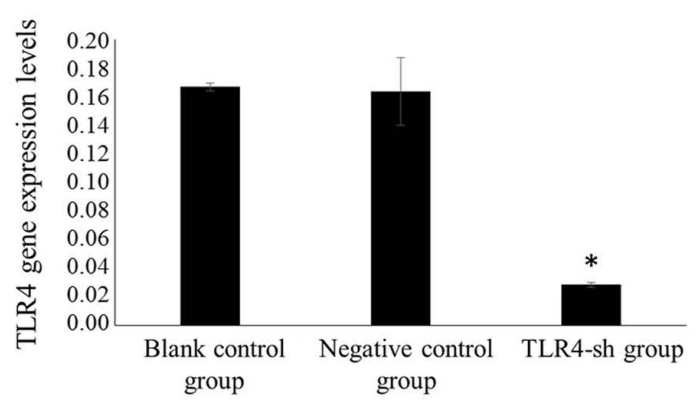

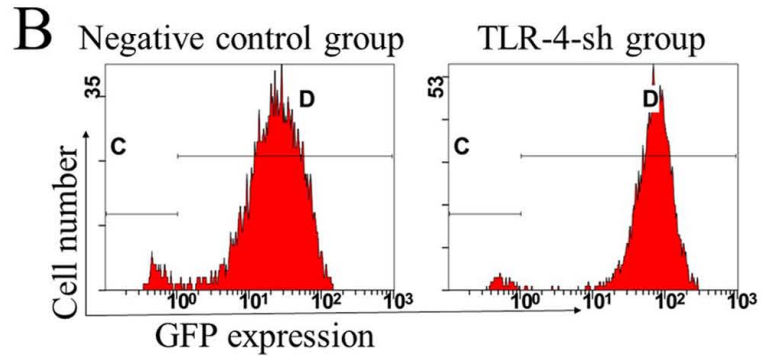

D

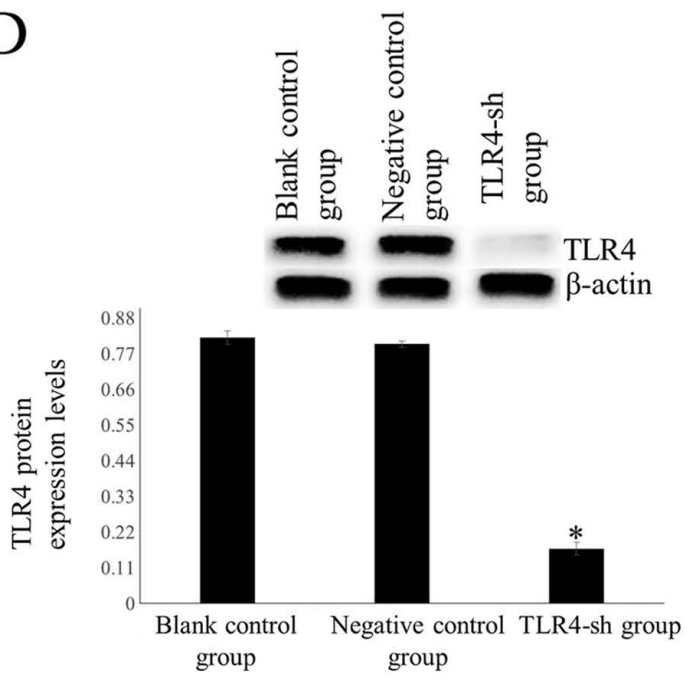

Figure 2. Identification of stably transfected cells using puromycin. Cells were treated with $600 \mathrm{ng} / \mathrm{ml}$ puromycin for 14 days. (A) Observing expression levels of green fluorescence using a fluorescence microscope (magnification, x100). (B) Flow cytometry was used to evaluate transfection efficiency. Transfection efficiency was $95.05 \pm 0.17$ and $94.75 \pm 0.72 \%$ in the H_TLR4-sh2 and NC groups, respectively. The letters "C" and "D" represent the gate of flow cytometry. Measuring expression levels of TLR4 (C) mRNA and (D) protein in transfected cells using fluorescence reverse transcription-quantitative PCR and western blot analysis, respectively. $n=3$. ${ }^{*} \mathrm{P}<0.01$ vs. U-87MG and U-87MG-NC. TLR4, toll-like receptor 4; sh, short hairpin RNA; NC, negative control; GFP, green fluorescent protein.

of cells transfected with TLR4-sh2 and NC plasmids were alive (Fig. 2A). Surviving cells represented stably transfected cells. Cells transfected with TLR4-sh2 and NC plasmids were labeled as U-87MG-Sh and U-87MG-NC cells, respectively.

Transfection efficiency was measured via flow cytometry. In the TLR4-sh and NC group, transfection efficiency was $95.05 \pm 0.17$ and $94.75 \pm 0.72 \%$, respectively (Fig. 2B). Fluorescence RT-qPCR results demonstrated that the TLR4 mRNA expression levels were significantly lower in the TLR4-sh group than that in $\mathrm{NC}$ and blank control groups $(\mathrm{P}<0.01$; Fig. 2C).

TLR4 protein expression levels are decreased in TLR4-sh-transfected cells. Western blot results demonstrated that TLR4 protein expression levels were significantly lower in the TLR4-sh group than in NC and blank control groups $(\mathrm{P}<0.01$; Fig. 2D).

Measuring cell cycle and apoptosis rate of transfected cells via flow cytometry. The percentage of cells in the $\mathrm{G}_{0 / 1}$ phase was significantly higher in the TLR4-sh than that in NC and blank control groups $(\mathrm{P}<0.01)$. By contrast, the PI was significantly lower in U-87MG-Sh cells than in U-87MG-NC and $\mathrm{U}-87 \mathrm{MG}$ cells $(\mathrm{P}<0.01)$. The percentage of the cells in the $\mathrm{G}_{0 / 1}$ phase and $\mathrm{PI}$ in $\mathrm{U}-87 \mathrm{MG}-\mathrm{NC}$ and $\mathrm{U}-87 \mathrm{MG}$ cells exhibited no significant difference ( $\mathrm{P}>0.05$; Fig. $3 \mathrm{~A})$.

The cell apoptosis rate was significantly higher in U-87MG-Sh cells than in U-87MG-NC and U-87MG cells $(\mathrm{P}<0.01)$ whereas no significant difference was observed in the apoptosis rates between U-87MG-NC and U-87MG cells (P>0.05; Fig. 3B).

TLR4 silencing decreases migration ability. Wound healing assay indicated that migration ability of the U-87MG-Sh cells was significantly lower than that of U-87MG-NC and U-87MG cells (Fig. 4).

TLR4 silencing inhibits cell proliferation. Results of the CCK-8 assay indicated that the proliferation inhibitory rates were $0.40 \pm 1.47,0.31 \pm 0.94$ and $28.94 \pm 1.31 \%$ in the blank, NC and TLR4-sh groups, respectively. The proliferation inhibitory rate of TLR4-sh group was significantly higher than that of blank and NC groups $(\mathrm{P}<0.01)$ (data not shown).

\section{Discussion}

Glioma is a type of primary brain cancer (22), which is characterized by high prevalence and gross invasion and is lethal to human health $(1,2)$. Resistance to conventional therapy (such as surgery, radiotherapy and chemotherapy) and the diffusely aggressive nature of glioma mean overall efficiency of glioma treatment is poor, and the average survival time of patients with high-grade glioma is $<1$ year (23). With the development of molecular biology, research has focused on immunotherapy against glioma (23). Therefore, it is necessary to determine the characteristics of immunotolerance and immunomodulation of glioma to develop an effective immunotherapy strategy. 


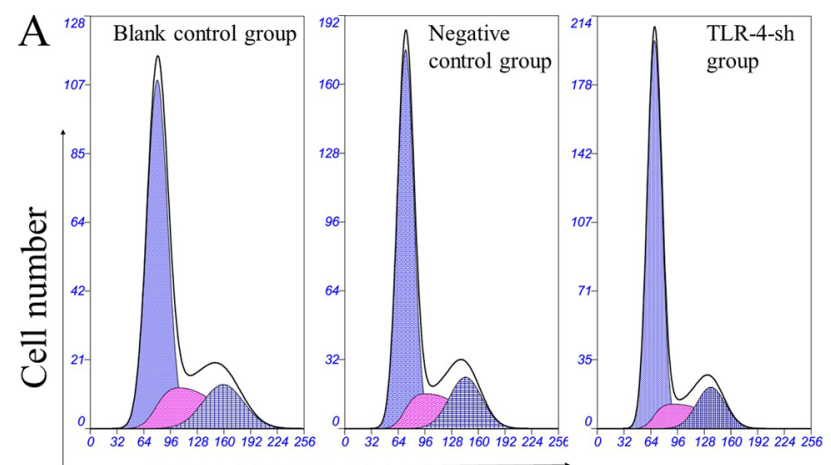

B

DNA content
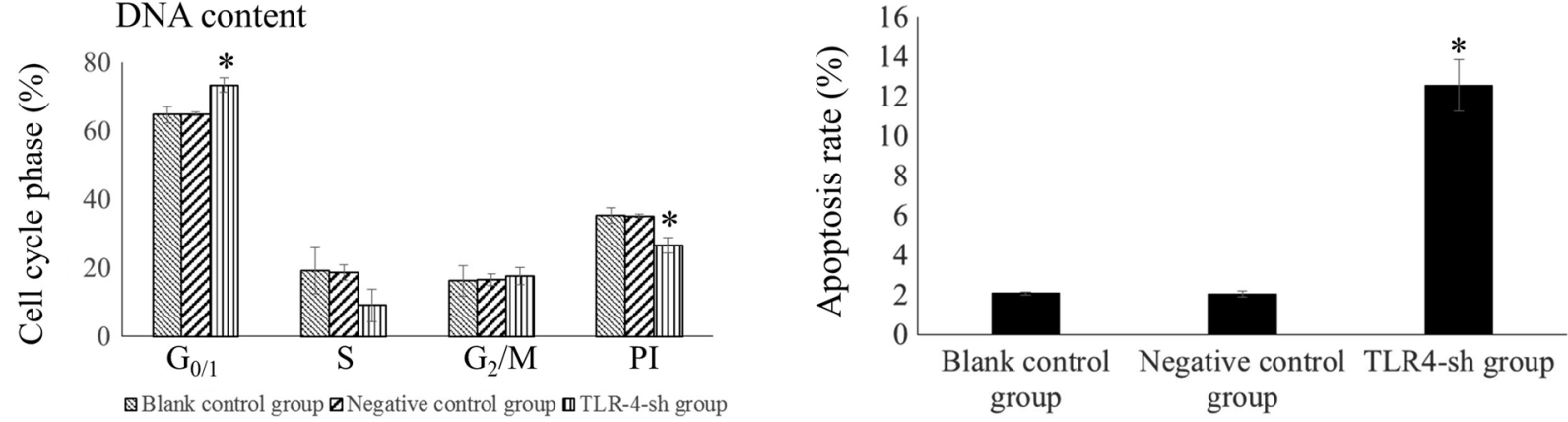

Figure 3. Evaluation of cell cycle and apoptosis rate of transfected cells using flow cytometry. (A) Cell cycle analysis of transfected, negative control and blank control cells. Propidium iodide staining was used to determine DNA concentration. Multicycle AV software was used to perform fit analysis of the DNA cell cycle and to calculate the percentage of cells in each phase. " $\mathrm{P}<0.01$ vs. blank and negative control. The percentage of $\mathrm{G}_{0 / 1}$ cells in the U-87MG-Sh group was significantly higher, whereas PI was significantly lower. This indicated that the proliferation activity of the U-87MG-Sh cells decreased significantly. (B) Evaluating cell apoptosis rate using flow cytometry. Measuring apoptosis rates in transfected and negative and blank control cells with flow cytometry. The apoptosis rate in the TLR4-sh group increased significantly. " $\mathrm{P}<0.01 \mathrm{vs.} \mathrm{blank}$ and negative control. TLR4, toll-like receptor 4; sh, short hairpin RNA; PI, proliferation index.

TLRs have been investigated as key PRRs in natural immunity and recognize certain highly conserved molecular structures of pathogens (24). Moreover, TLRs are the bridge between innate immunity and acquired immunity and are important to prevent biological pathogenic factor infection (25).

TLRs are type I transmembrane proteins in mammals and they are a family of conserved transmembrane signaling receptors regulating innate immunity. TLRs are a member of the PRR family and are associated with the recognition of PAMPs (26). TLR4 was the first identified human cell TLR homologous to Drosophila, and is therefore the most studied TLR (27). To date, 13 types of TLRs (TLR 1-13) have been identified in the human body (28).

Although TLRs mediate innate immunity, they are not unique to the innate immune system: In addition to immune cells [monocytes/macrophages, T/B lymphocytes and dendritic cells (29)], they are also expressed in certain non-immune cells, such as endothelial (30), smooth muscle (31) and tumor cells (32). TLR expression levels in tumor cells are key for tumorigenesis and progression, and this is an important topic in tumor research (33). Among TLRs, TLR4 is closely associated with tumors; high expression levels of TLR4 accelerate tumor proliferation and mediate tumor immune escape, for example in colon cancer, lung cancer and oral squamous cell carcinoma (34-36). Pandey et al (37) investigated TLR4 polymorphisms and expression level patterns and reported that TLR4 expression levels in different types of solid tumor tissue promote tumor growth, invasion and metastasis. Therefore, TLR4 expression levels in different tumor types may serve as a marker for tumor proliferation, differentiation, metastasis, prognosis and patient survival. Chen et al (38) reported that TLR4 is associated with liver cancer development; the activated TLR4/Nanog oncogenic pathway is associated with the suppression of cytostatic TGF- $\beta$ signaling and may serve as a therapeutic target for hepatitis $\mathrm{C}$ virus-associated hepatocellular carcinoma (HCC). Yao et al (39) reported that the TLR4/STAT3 signaling pathway participates in the carcinogenesis, development, invasion and metastasis of liver cancer. The authors also demonstrated that $\mathrm{M}_{2}$-polarized macrophages facilitate the migration and epithelial-mesenchymal transition of HCC cells via the TLR4/STAT3 signaling pathway, suggesting that TLR4 may be a novel therapeutic target. Szajnik et al (40) demonstrated that the TLR4/MyD88 signaling pathway promotes ovarian cancer development, drug resistance and immune escape. Zhang and Zhang (41) reported that Foxp3 and TLR4 are highly expressed in cervical cancer cells and are associated with clinical stage and lymph node metastasis; Foxp3 and TLR4 may be useful biomarkers for predicting the prognosis of patients and treating cervical cancer. Zhan et al (42) revealed that the molecular factors TLR4 and TLR 3 affect the progression of lung cancer by regulating autophagy, which may be a potential treatment strategy for lung cancer. Li et al (43) reported that TLR4 is highly expressed in breast cancer tissue and promotes breast cancer metastasis via the AKT/GSK3 $\beta / \beta$-catenin pathway, which is stimulated by lipopolysaccharide. Numerous studies have proved that TLR4 is associated with tumors $(44,45)$, but there are few studies on the association between TLR4 and the occurrence and development of glioma. Hence, the present study aimed to elucidate the association between TLR4 and the 

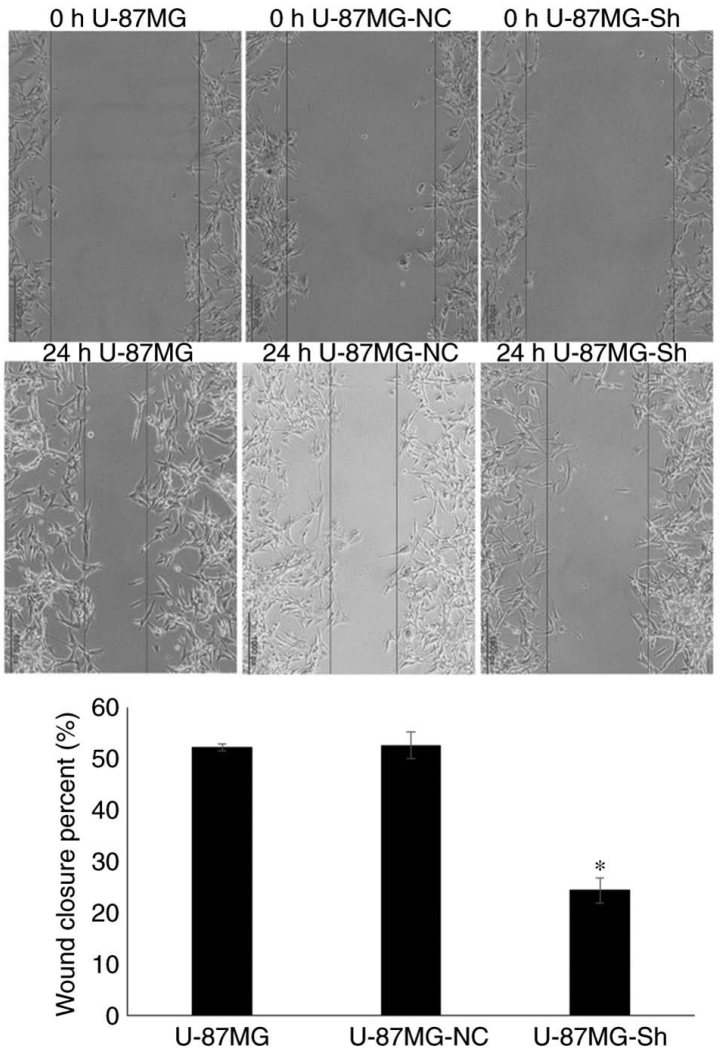

Figure 4. Evaluation of cell migration ability using wound healing assay, viewed under an inverted microscope (magnification, $\mathrm{x} 100$ ). ${ }^{*} \mathrm{P}<0.01$ vs. U-87MG and U-87MG-NC. NC, negative control; Sh, short hairpin RNA.

occurrence and development of glioma in vitro, and to provide experimental support to further investigate the pathogenesis of glioma.

In the present study, TLR4 gene expression levels in the human glioma cell line U-87MG were silenced by gene interference. The use of only one cell line was a potential limitation of the present study: In future investigations, multiple glioma cell lines should be used to verify the regulatory effect of TLR4 on proliferation. In the present study, a total of three interference plasmids were designed for the human TLR4 gene. After $48 \mathrm{~h}$ transfection, flow cytometry detection demonstrated that the transfection and silencing efficiency of TLR4-sh2 was the highest. Therefore, TLR4-sh2 interference plasmids were selected for subsequent experiments. The transfection efficiency of TLR4-sh2 interference and NC plasmid were $95.05 \pm 0.17$ and $94.75 \pm 0.72 \%$, respectively. Results of fluorescence RT-qPCR revealed that the TLR4 gene expression levels in U-87MG-sh cells decreased significantly, which revealed that TLR4 gene silencing in U-87MG cells was successful.

The present study investigated the association between TLR4 and U-87MG cell proliferation. After silencing TLR4 gene expression levels in U-87MG cells via gene interference, flow cytometry indicated that the PI of U-87MG-sh cells declined and the $G_{0 / 1}$ phase of the cell cycle extended significantly, demonstrating that TLR4 gene silencing significantly inhibited the proliferation of U-87MG cells. Following TLR4 gene silencing, CCK-8 demonstrated that U-87MG cell proliferation was significantly inhibited, which was consistent with the flow cytometry results. The absence of colony formation assay was a potential limitation of the present study: In future investigations, colony formation assay should be used to verify the CCK-8 results. Following TLR4 gene silencing in U-87MG cells, flow cytometry revealed that the apoptotic rate of U-87MG cells increased significantly, indicating that silencing the TLR4 gene inhibited growth and induced apoptosis in the glioma cell line U-87MG. TLR4 may therefore represent a target for the development of anti-glioma drugs and treatment methods.

TLR4-sh interference plasmids were successfully transfected into U-87MG cells via liposome transfection and stably transfected cells were screened using puromycin to establish a glioma cell model with low TLR4 gene expression levels. The present study demonstrated that the TLR4 gene is associated with proliferation and apoptosis regulation in U-87MG cells. Silencing the TLR4 gene in U-87MG cells significantly inhibited cell proliferation and induced U-87MG cell apoptosis, providing an experimental basis for the development of anti-glioma drugs and therapeutic methods targeting the TLR4 gene. The absence of clinical data (expression levels in tissue, association with patient prognosis) was a limitation of the present study. The molecular mechanisms underlying growth inhibition and cell apoptosis induction of $\mathrm{U}-87 \mathrm{MG}$ cells by silencing the TLR4 gene are complex, necessitating further study in the future.

\section{Acknowledgements}

Not applicable.

\section{Funding}

The present study was supported by the Excellent Talent Project in Clinical Medicine funded by Hebei provincial government in 2017 [grant no. Jicaishe(2017)46].

\section{Availability of data and materials}

The datasets used and/or analyzed during the current study are available from the corresponding author on reasonable request.

\section{Authors' contributions}

YL performed the experiments and wrote the manuscript. YJ performed the experiments and statistical analysis. JL, YC and $\mathrm{XH}$ performed the experiments. LL designed the study, performed the experiments and revised the manuscript. All authors read and approved the final version of the manuscript.

\section{Ethics approval and consent to participate}

Not applicable.

\section{Patient consent for publication}

Not applicable.

\section{Competing interests}

The authors declare that they have no competing interests. 


\section{References}

1. Davis ME: Epidemiology and overview of gliomas. Semin Oncol Nurs 34: 420-429, 2018.

2. Ostrom QT, Gittleman H, Stetson L, Virk SM and BarnholtzSloan JS: Epidemiology of gliomas. Cancer Treat Res 163: 1-14, 2015.

3. Ostrom QT, Gittleman H, Liao P, Rouse C, Chen Y, Dowling J, Wolinsky Y, Kruchko C and Barnholtz-Sloan J: CBTRUS statistical report: Primary brain and central nervous system tumors diagnosed in the United States in 2007-2011. Neuro Oncol 16 (Suppl 4): iv1-iv63, 2014.

4. Rasmussen BK, Hansen S, Laursen RJ, Kosteljanetz M, Schultz H, Nørgård BM, Guldberg R and Gradel KO: Epidemiology of glioma: Clinical characteristics, symptoms, and predictors of glioma patients grade I-IV in the the Danish neuro-oncology registry. J Neurooncol 135: 571-579, 2017.

5. Kawai T and Akira S: Toll-like receptors and their crosstalk with other innate receptors in infection and immunity. Immunity 34 : 637-650, 2011

6. Kumar H, Kawai T and Akira S: Toll-like receptors and innate immunity. Biochem Biophys Res Commun 388: 621-625, 2009.

7. Hua $Z$ and Hou B: TLR signaling in B-cell development and activation. Cell Mol Immunol 10: 103-106, 2013.

8. Kawai T and Akira S: TLR signaling. Semin Immunol 19: 24-32, 2007.

9. Seydoux E, Liang H, Dubois Cauwelaert N, Archer M, Rintala ND, Kramer R, Carter D, Fox CB and Orr MT: Effective combination adjuvants engage both TLR and inflammasome pathways to promote potent adaptive immune responses. J Immunol 201: 98-112, 2018

10. Tian S, Wang M, Liu C, Zhao H and Zhao B: Mulberry leaf reduces inflammation and insulin resistance in type 2 diabetic mice by TLRs and insulin signalling pathway. BMC Complement Altern Med 19: 326, 2019.

11. Dickinson SE and Wondrak GT: TLR4-directed molecular strategies targeting skin photodamage and carcinogenesis. Curr Med Chem 25: 5487-5502, 2018.

12. Wang YH, Cao YW, Yang XC, Niu HT, Sun LJ, Wang XS and Liu J: Effect of TLR4 and B7-H1 on immune escape of urothelial bladder cancer and its clinical significance. Asian Pac J Cancer Prev 15: 1321-1326, 2014.

13. Monlish DA, Bhatt ST and Schuettpelz LG: The role of toll-like receptors in hematopoietic malignancies. Front Immunol 7: 390, 2016.

14. Dajon M, Iribarren K and Cremer I: Toll-like receptor stimulation in cancer: A pro- and anti-tumor double-edged sword. Immunobiology 222: 89-100, 2017.

15. Makkar S, Riehl TE, Chen B, Yan Y, Alvarado DM, Ciorba MA and Stenson WF: Hyaluronic acid binding to TLR4 promotes proliferation and blocks apoptosis in colon cancer. Mol Cancer Ther 18: 2446-2456, 2019.

16. Sun NK, Huang SL, Chang TC and Chao CC: TLR4 and NFאB signaling is critical for taxol resistance in ovarian carcinoma cells. J Cell Physiol 233: 2489-2501, 2018.

17. Shetab Boushehri MA and Lamprecht A: TLR4-based immunotherapeutics in cancer: A review of the achievements and shortcomings. Mol Pharm 15: 4777-4800, 2018.

18. Dapito DH, Mencin A, Gwak GY, Pradere JP, Jang MK, Mederacke I, Caviglia JM, Khiabanian H, Adeyemi A, Bataller R, et al: Promotion of hepatocellular carcinoma by the intestinal microbiota and TLR4. Cancer Cell 21: 504-516, 2012.

19. Allen M, Bjerke M, Edlund H, Nelander S and Westermark B: Origin of the U87MG glioma cell line: Good news and bad news. Sci Transl Med 8: 354re3, 2016.

20. Zhou T, Li Y, Yang L, Liu L, Ju Y and Li C: Silencing of ANXA3 expression by RNA interference inhibits the proliferation and invasion of breast cancer cells. Oncol Rep 37: 388-398, 2017.

21. Livak KJ and Schmittgen TD: Analysis of relative gene expression data using real-time quantitative PCR and the 2(-Delta Delta C(T)) method. Methods 25: 402-408, 2001

22. Ostrom QT, Bauchet L, Davis FG, Deltour I, Fisher JL, Langer CE, Pekmezci M, Schwartzbaum JA, Turner MC, Walsh KM, et al: The epidemiology of glioma in adults: A 'state of the science' review. Neuro Oncol 16: 896-913, 2014.

23. Lim M, Xia Y, Bettegowda C and Weller M: Current state of immunotherapy for glioblastoma. Nat Rev Clin Oncol 15: 422-442, 2018

24. Satoh T and Akira S: Toll-like receptor signaling and its inducible proteins. Microbiol Spectr 4, 2016.
25. Steinhagen F, Kinjo T, Bode C and Klinman DM: TLR-based immune adjuvants. Vaccine 29: 3341-3355, 2011.

26. Kumar V: Toll-like receptors in the pathogenesis of neuroinflammation. J Neuroimmunol 332: 16-30, 2019.

27. Medzhitov R, Preston-Hurlburt P and Janeway CA Jr: A human homologue of the Drosophila Toll protein signals activation of adaptive immunity. Nature 388: 394-397, 1997.

28. Vijay K: Toll-like receptors in immunity and inflammatory diseases: Past, present, and future. Int Immunopharmacol 59: 391-412, 2018.

29. Mikulic J, Longet S, Favre L, Benyacoub J and Corthesy B: Secretory IgA in complex with Lactobacillus rhamnosus potentiates mucosal dendritic cell-mediated Treg cell differentiation via TLR regulatory proteins, RALDH2 and secretion of IL-10 and TGF- $\beta$. Cell Mol Immunol 14: 546-556, 2017.

30. Tang AT, Choi JP, Kotzin JJ, Yang Y, Hong CC, Hobson N, Girard R, Zeineddine HA, Lightle R, Moore T, et al: Endothelial TLR4 and the microbiome drive cerebral cavernous malformations. Nature 545: 305-310, 2017.

31. Yin Q, Jiang D, Li L, Yang Y, Wu P, Luo Y, Yang R and Li D: LPS promotes vascular smooth muscle cells proliferation through the TLR4/Rac1/Akt signalling pathway. Cell Physiol Biochem 44: 2189-2200, 2017.

32. Fu HY, Li C, Yang W, Gai XD, Jia T, Lei YM and Li Y: FOXP3 and TLR4 protein expression are correlated in non-small cell lung cancer: Implications for tumor progression and escape. Acta Histochem 115: 151-157, 2013.

33. Grimmig T, Matthes N, Hoeland K, Tripathi S, Chandraker A Grimm M, Moench R, Moll EM, Friess H, Tsaur I, et al: TLR7 and TLR8 expression increases tumor cell proliferation and promotes chemoresistance in human pancreatic cancer. Int J Oncol 47: 857-866, 2015.

34. Xiao T, Wu S, Yan C, Zhao C, Jin H, Yan N, Xu J, Wu Y, Li C, Shao Q and Xia S: Butyrate upregulates the TLR4 expression and the phosphorylation of MAPKs and NK- $\kappa \mathrm{B}$ in colon cancer cell in vitro. Oncol Lett 16: 4439-4447, 2018.

35. $\mathrm{Li} \mathrm{C}, \mathrm{Li} \mathrm{H}$, Jiang $\mathrm{K}, \mathrm{Li} \mathrm{J}$ and Gai X: TLR4 signaling pathway in mouse Lewis lung cancer cells promotes the expression of TGF- $\beta 1$ and IL-10 and tumor cells migration. Biomed Mater Eng 24: 869-875, 2014.

36. Ren WH, Zhang LM, Liu HQ, Gao L, Chen C, Qiang C, Wang XL, Liu CY, Li SM, Huang C, et al: Protein overexpression of CIRP and TLR4 in oral squamous cell carcinoma: An immunohistochemical and clinical correlation analysis. Med Oncol 31: 120, 2014.

37. Pandey N, Chauhan A and Jain N: TLR4 polymorphisms and expression in solid cancers. Mol Diagn Ther 22: 683-702, 2018.

38. Chen CL, Tsukamoto H, Liu JC, Kashiwabara C, Feldman D, Sher L, Dooley S, French SW, Mishra L, Petrovic L, et al: Reciprocal regulation by TLR 4 and TGF- $\beta$ in tumor-initiating stem-like cells. J Clin Invest 123: 2832-2849, 2013.

39. Yao RR, Li JH, Zhang R, Chen RX and Wang YH: M2-polarized tumor-associated macrophages facilitated migration and epithelial-mesenchymal transition of HCC cells via the TLR4/STAT3 signaling pathway. World J Surg Oncol 16: 9, 2018.

40. Szajnik M, Szczepanski MJ, Czystowska M, Elishaev E, Mandapathil M, Nowak-Markwitz E, Spaczynski M and Whiteside TL: TLR4 signaling induced by lipopolysaccharide or paclitaxel regulates tumor survival and chemoresistance in ovarian cancer. Oncogene 28: 4353-4363, 2009.

41. Zhang $\mathrm{H}$ and Zhang S: The expression of Foxp3 and TLR4 in cervical cancer: Association with immune escape and clinical pathology. Arch Gynecol Obstet 295: 705-712, 2017.

42. Zhan Z, Xie X, Cao H, Zhou X, Zhang XD, Fan H and Liu Z: Autophagy facilitates TLR4- and TLR3-triggered migration and invasion of lung cancer cells through the promotion of TRAF6 ubiquitination. Autophagy 10: 257-268, 2014.

43. Li J, Yin J, Shen W, Gao R, Liu Y, Chen Y, Li X, Liu C, Xiang R and Luo N: TLR4 promotes breast cancer metastasis via Akt/GSK3 $\beta / \beta$-catenin pathway upon LPS stimulation. Anat Rec (Hoboken) 300: 1219-1229, 2017.

44. Kim KH, Jo MS, Suh DS, Yoon MS, Shin DH, Lee JH and Choi KU: Expression and significance of the TLR4/MyD88 signaling pathway in ovarian epithelial cancers. World J Surg Oncol 10: 193, 2012.

45. Zhou Q, Wang C, Wang X, Wu X, Zhu Z, Liu B and Su L: Association between TLR4 (+896A/G and $+1196 \mathrm{C} / \mathrm{T})$ polymorphisms and gastric cancer risk: An updated meta-analysis. PLoS One 9: e109605, 2014. 